\title{
COMPARISON OF SOFTWARE FOR AIRBORNE LASER SCANNING DATA PROCESSING IN SMART CITY APPLICATIONS
}

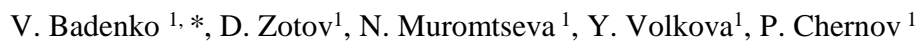 \\ ${ }^{1}$ Peter the Great St. Petersburg Polytechnic University, Civil Engineering Institute, 195251 Polytechnicheskaya 29, St. Petersburg, \\ Russian Federation, - (badenko_vl, zotov_dk, muromtseva_ns, volkova_yuv)@spbstu.ru, chernov_pv@edu.spbstu.ru
}

Commission V, WG V/7

KEY WORDS: airborne laser scanning data, data processing, classification, software comparison, smart city application

\begin{abstract}
:
Problems of processing of point clouds of airborne laser scanning using different software for Smart City projects are considered. Results of comparison of suitable software on the base of a test point cloud are presented. For comparison we had chosen a criterion for how results of point cloud processing can be used in the smart city application. The following software were chosen for comparison: Erdas IMAGINE, ENVI Lidar, TerraSolid (without Terraslave), GlobalMapper, Autodesk InfraWorks. Comparison have been conducted in qualitative and quantitative terms. The results presented allowed us to create recommendations on the usage of specific software for airborne laser scanning data processing for Smart City projects.
\end{abstract}

\section{INTRODUCTION}

All type of laser scanning technologies (terrestrial, mobile, airborne) are a very popular and powerful tool for urban territory surveys to collect data during Smart City projects implementation (Balado et al., 2018; Hu et al., 2018; Li et al., 2018; Julin et al., 2018; Badenko et al., 2019; Yang and Lee, 2019). Airborne LIDAR (Light Identification Detection and Ranging) is one of the optimal modern surveying methods for urban environment (Jochem et al., 2012; Tomljenovic et al., 2015; Yan et al., 2015). In particular, this technology is effectively used to create digital terrain models (DTM) taking into account vegetation landcover and has better accuracy and quality than SRTM (Shuttle Radar Topography Mission) (Robinson et al., 2014; de Carvalho et al., 2014; Nevalainen et al., 2016; Badenko et al., 2018a; Tran et al., 2018). Also, airborne laser scanning (ALS) technology gives more information, that photogrammetry, because common this system can process more than 5-8 reflections from one laser beam, so the technology allows us to recognize DTM despite vegetation, and to define attributes of vegetation (Gorte et al., 2005; Muecke et al., 2010; Penner et al., 2015; Badenko et al., 2018b).

Analysis of the efficiency of the laser scanning data processing technologies continues to be a relevant research topic (Kaartinen et al., 2012; Xiao et al., 2016). In many cases processing of airborne laser scanning datd is much efficiency, then processing of mobile laser scanning (MLS) data (Zhou and Vosselman, 2012; Wang et al., 2018). For example, for processing of $100 \mathrm{~km}$ (3000 ha) MLS track survey it was needed more than $1 \mathrm{~Tb}$ space on a hard drive (for multi-head systems) and more than one week for processing (including registration and classification). The same ALS tile was needed only $20 \mathrm{~Gb}$ on a hard drive, and about few hours for creation of classification.

The objective of this paper is a comparative study of approaches and software to processing of airborne laser scanning for Smart
City applications. For case study presented we have been used education versions of following software: Erdas IMAGINE, ENVI Lidar, Terrasolid (without Terraslave), GlobalMapper, Autodesk InfraWorks.

\section{CASE STUDY}

\subsection{Initial airborne laser scanning point cloud}

For Smart City application including infrastructure renovations the best data source is airborne LIDAR. Initial airborne laser scanning point cloud for comparison test experiments is shown in Figure 1.

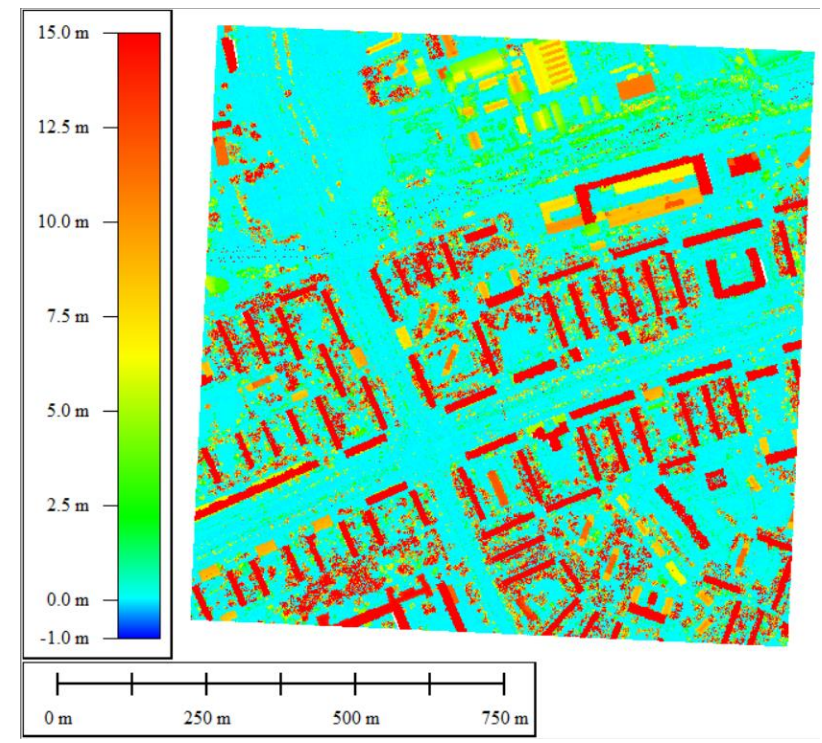

Figure 1. Initial airborne laser scanning point cloud

\footnotetext{
* Corresponding author
} 
The point cloud had obtained by airborne laser scanning the of territory of Saint-Petersburg, Russia (one square kilometre). During scanning a complicated flight-track-adjustment software as one of the great advantage of ALS have been used (Lindenthal et al., 2011). The resolution (point spacing) of the cloud is about $0.15-0.25$ meters. There are up to 6 returns from each laser beam in this cloud. The total size of the cloud is about 22 million points.

\subsection{Segmentation and classification of the point cloud}

Our first step was segmentation and classification of the point cloud. Classes, that are need for Smart City applications are following: Ground, Low/Medium/High Vegetation, Buildings, Model Keypoints, Wires, Vegetation Taxonomy, Roads (Zubizarreta et al., 2015; Angelidou, 2017). The features for automatic classification using software in question are shown in Table 1 .

\begin{tabular}{|l|l|}
\hline $\begin{array}{l}\text { Feature type } \\
\text { (classes) }\end{array}$ & \multicolumn{1}{|c|}{ Software which can classify the features } \\
\hline Ground & $\begin{array}{l}\text { Erdas, ENVI, Terrasolid, GlobalMapper, } \\
\text { Infraworks }\end{array}$ \\
\hline Vegetation & Erdas, ENVI, Terrasolid, GlobalMapper \\
\hline Buildings & $\begin{array}{l}\text { Erdas, ENVI, Terrasolid, GlobalMapper, } \\
\text { Infraworks }\end{array}$ \\
\hline Wires & ENVI, Terrasolid, GlobalMapper \\
\hline Taxonomy & ENVI, Terrasolid, GlobalMapper \\
\hline Roads & ENVI, Terrasolid, Infraworks \\
\hline
\end{tabular}

Table 1. Abilities for classification of software in question

\subsection{Comparison of software on point cloud classification task. Qualitative approach}

\section{ENVI Lidar}

For this software was needed for classification about 7 minutes (the software can use all 16 CPU threads). Result of automatic classification in ENVI Lidar is shown in Figure 2.

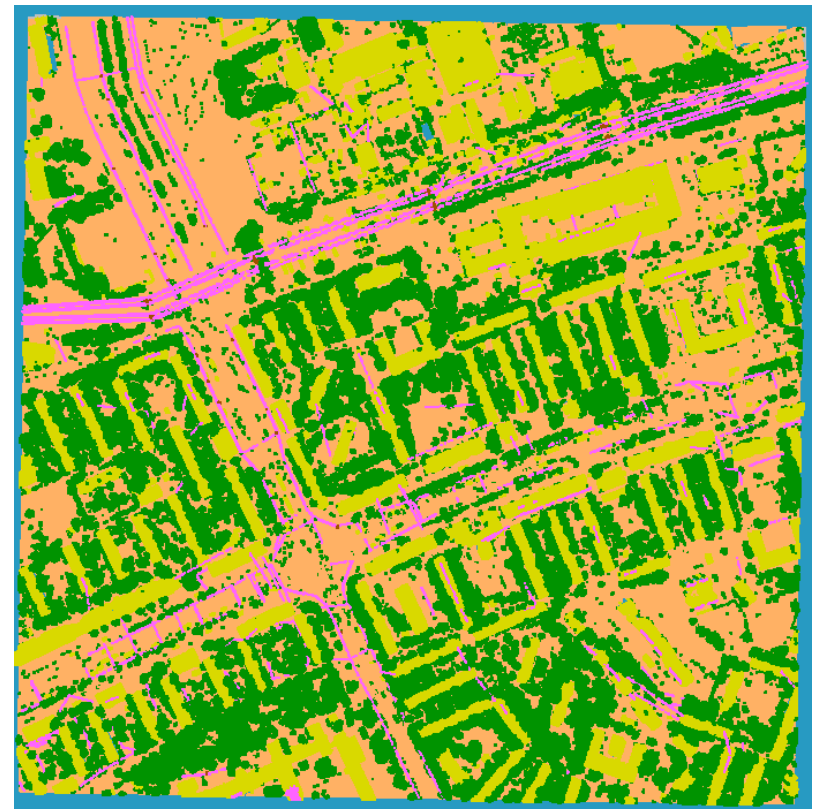

Figure 2. Result of automatic classification by ENVI Lidar
Also, there were extracted some vector features, like power wire-lines, buildings footprints with buildings height attribute. Quality of the power wire-lines is enough, but some buildings are bad-shaped. The 3D visualization is the best of all in comparison research. Vegetation taxonomy is rather good, because there is difference between hardwood and coniferous trees.

After classification ENVI Lidar provides wide opportunities for visualization. A $3 \mathrm{~d}$ visualization after classification of the test laser scanning point cloud is shown in Figure 3. The walls of the houses are automatically depicted with a standard texture including windows only for a more realistic display. Individual trees with real crown shape are clearly visible.

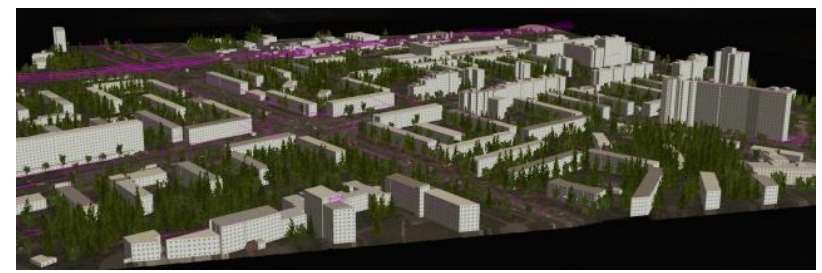

Figure 3. 3D visualisation in ENVI Lidar environment

\section{Global Mapper}

For this software was needed for classification about 18 minutes. There were extracted some vector features, like power wire-lines, buildings footprints with buildings height. Quality of the power wire-lines recognition is enough, but some buildings are bad-shaped. Result of automatic classification in Global mapper is shown in Figure 4. A 3d visualization after classification of the test laser scanning point cloud $3 \mathrm{~d}$ is good (Figure 5), but worse than ENVI Lidar visualization, because the texture for the walls and the shape of the trees are less realistic.

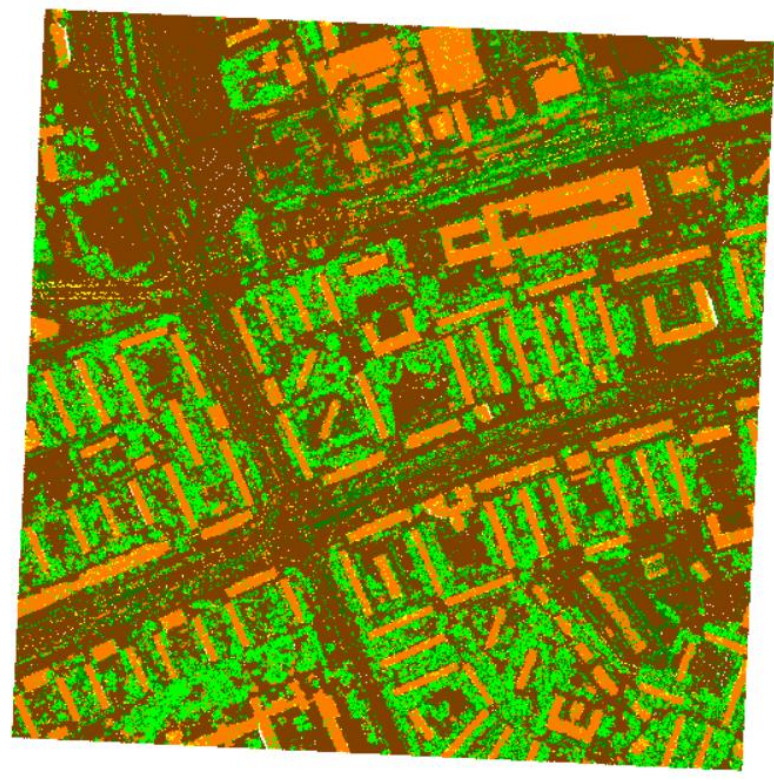

Figure 4. Automatic classification in Global mapper 


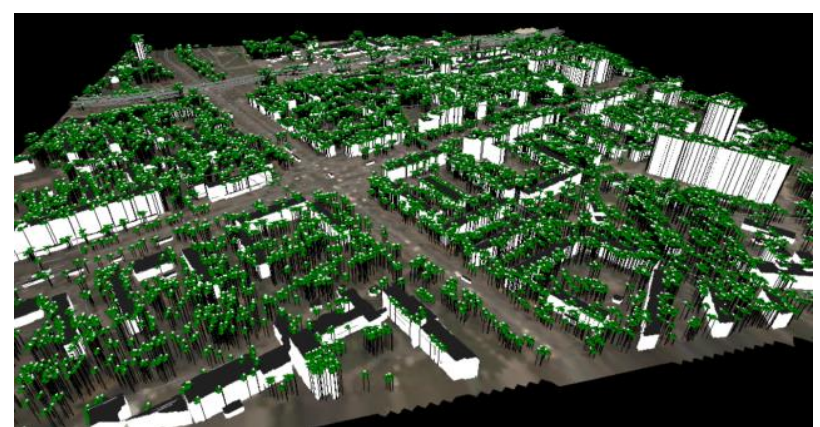

Figure 5. 3d visualization in Global mapper

\section{Terrasolid}

Software uses the MisroStation environment (Kaartinen et al., 2012). For this software was needed for classification about 20 minutes (without TerraSlave). Classification accuracy was rather good (Figure 6). There were extracted vector features, like wire-lines, buildings footprints with buildings height attribute. Also there were extracted roof slopes (Figure 7), that is very necessary to automatic building type detection. Some buildings are bad-shaped. There is no embedded $3 \mathrm{~d}$ visualization. Roads were also extracted.

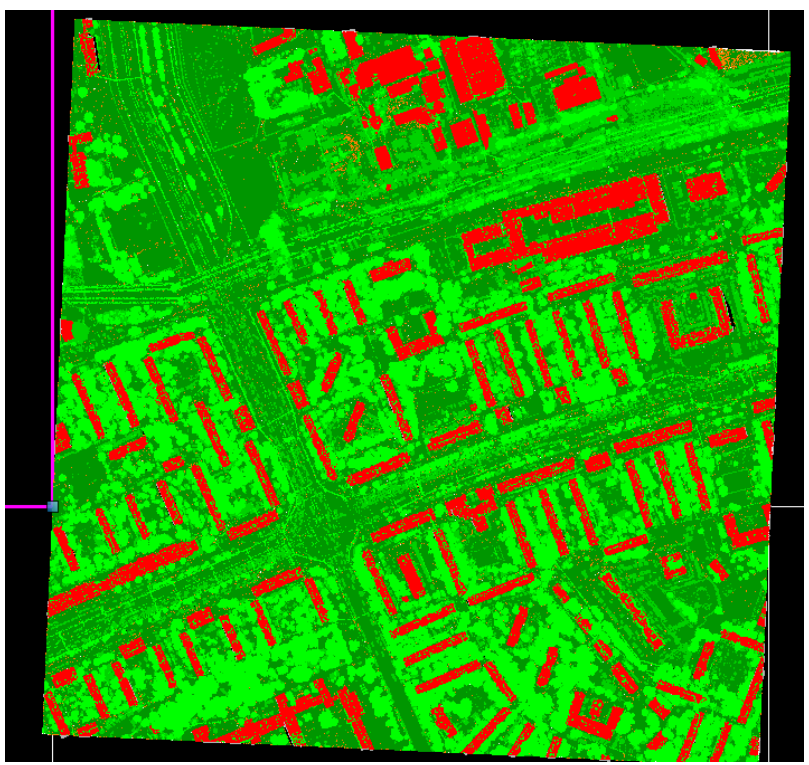

Figure 6. Automatic classification in Terrasolid.

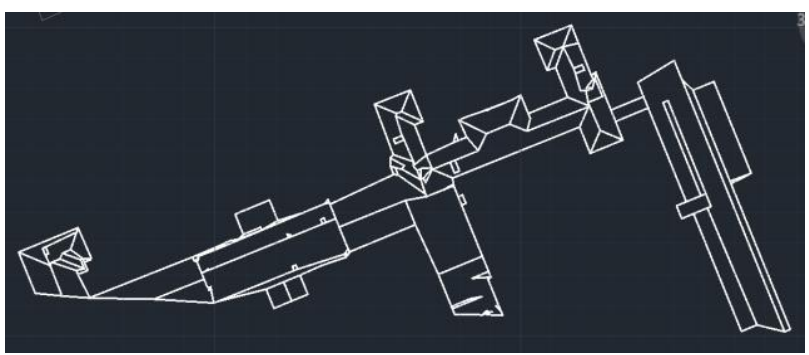

Figure 7. Roof slopes preview

\section{Erdas IMAGINE}

For this software was needed for classification about 25 minutes. The classification accuracy obtained in Erdas IMAGINE software was also quite good (Figure 8). No vector features were extracted. But there were extracted vegetation features, using NDVI (Normalized Difference Vegetation Index) (Chen et al., 2012). The calculation of the index was made possible because during the survey there was an airborne based multispectral camera.

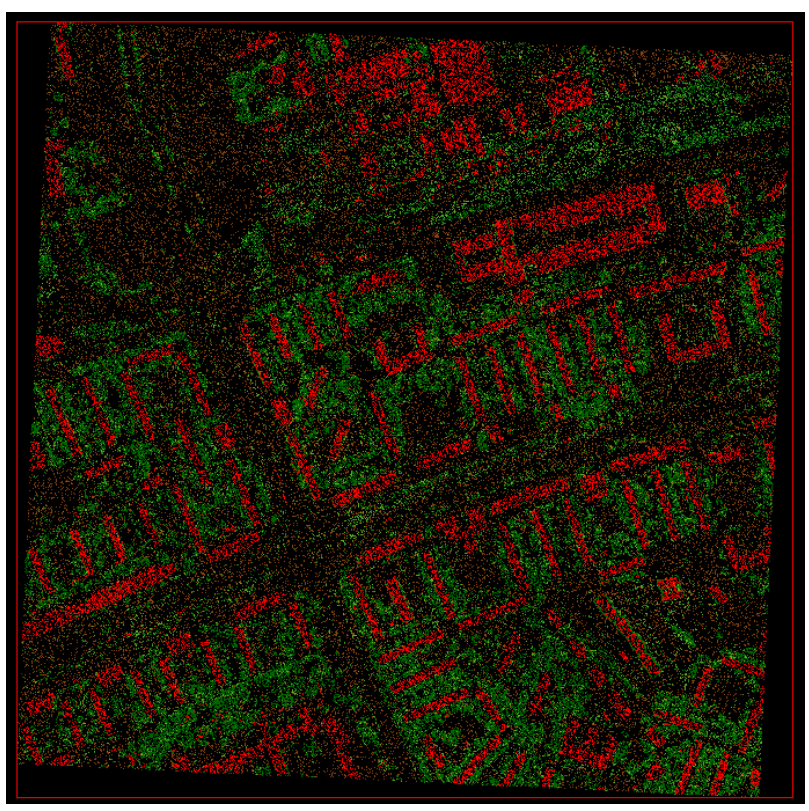

Figure 8. Automatic classification in Erdas IMAGINE.

\section{Autodesk InfraWorks}

InfraWorks can't proceed point cloud classification, and used only free data, like space photos and SRTM map. DTM is awful, no trees were extracted. But houses footprints were very good, because of smoothing (Figure 9).

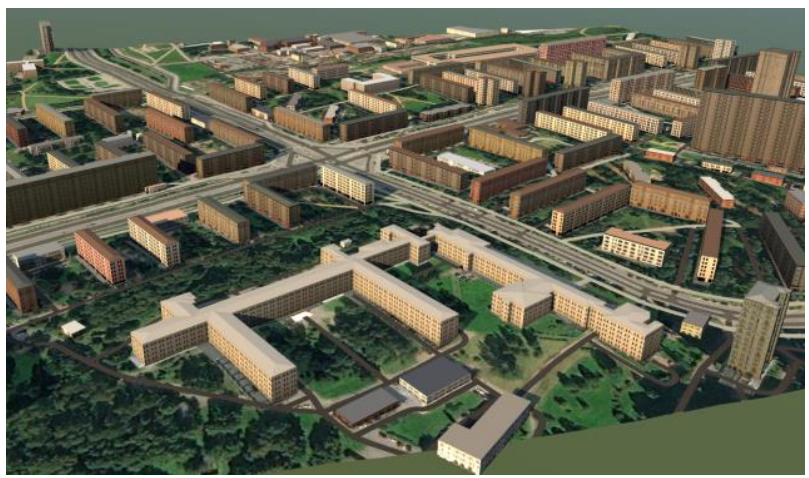

Figure 9. 3d model in InfraWorks

But buildings height was awful and often did not coincide with the real (Figure 10). This software allows one to get very quickly the raw result, analyse the study area and create information only to support primary decision in Smart City projects. 

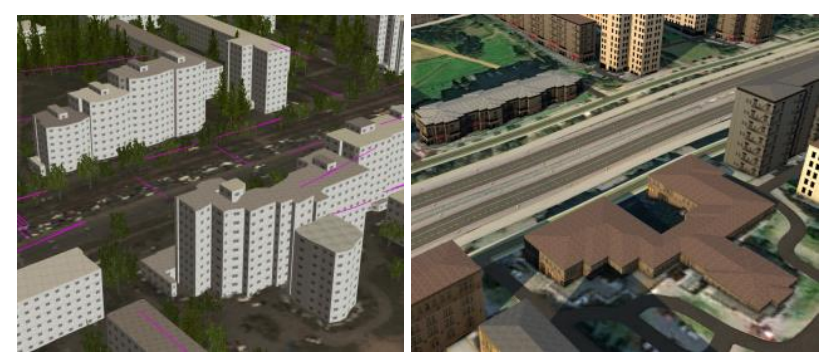

Figure 10. Building height difference between lidar-based model (left) and InfraWorks (right)

\subsection{Comparison of software on point cloud classification task. Quantitative approach}

For quantitative comparison a following approach was used.

The following classes were used for comparison (\# Cl):
1. Low points
2. Unclassified points
3. Low vegetation
4. High vegetation
5. Wires
6. Ground points
7. Buildings

It must be pointed out that Low points usually includes point below surface ("aerial points") and lone points. Envi Lidar software had merged 1,2 and 3 classes during export. Erdas Imagine also had merged 1, 2, 3 and 4 classes during export. The result of comparison of number of points in each class $(\# \mathrm{Cl})$ for test point cloud (Figure 1) are presented in Table 2.

\begin{tabular}{|c|c|c|c|c|}
\hline \# Cl & \multicolumn{4}{|c|}{ Number of points } \\
\hline & Terrasolid & Global Mapper & Envi Lidar & Erdas Imagine \\
1 & 196 & 591 & 659220 & 5849578 \\
2 & 54967 & 66149 & - & - \\
3 & 7570206 & 1164206 & - & - \\
4 & 3271387 & 5933098 & 5443212 & - \\
5 & 36464 & 250927 & 55139 & 10764 \\
6 & 3271387 & 10005274 & 10987681 & 10881678 \\
7 & 2510506 & 2253058 & 3185710 & 3456686 \\
\hline
\end{tabular}

Table 2. Number of points in each class for different software

Some comments for Table 2 must be added. For all software sometimes the following happens. For Terrasolid: 1) cars, buildings footprints, semi-row ground points had included in class 3 ; 2) trees, wires, cars, house walls had included in class 4. For Global Mapper: 1) cars parts/whole, buildings footprints had included in class 3 ; 2) trees, wires, cars, house walls had included in class 4; 3) roof parts had included in class 5;4) some big cars had recognized as buildings (class 7). For Envi Lidar: 1) cars, wires, house parts had included in classes 1, 2, 3; 2) trees, cars, wire poles had included in class 4;3) roofs, walls, big cars had included in class 7. For Erdas imagine: 1) trees, cars, wires, building walls had included in class 1,2,3,4. It should also be specifically noted that the 5 class (Wires) of Envi Lidar is of excellent quality.

\section{CONCLUSIONS}

The results of software comparison on the base of test airborne laser scanning point cloud processing have presented. The comparison criterion is how results of point cloud processing can be used in the Smart City application. The following software was chosen for comparison: Erdas IMAGINE, ENVI
Lidar, TerraSolid (without Terraslave), Global Mapper, Autodesk InfraWorks. We also tested the Esri City Engine. This powerful software is directly connected to the most popular GIS and therefore Esri City Engine is convenient for regional planning tasks. However, this software is not always well suited for solving engineering problems and working slower than others.

Recommendations on the usage of specific software for airborne laser scanning data processing for Smart City projects are following:

- ENVI Lidar software allows us to quickly and qualitatively classify, extract the footprints of buildings, power-lines and high vegetation. Other post-processing and uploading of data is practically not provided. This software is very useful for realistic visualization.

- The Global mapper software produces a qualitative (close to semi-automatic) classification, but because of the work in one stream, it has low performance. It is recommended to use this software if you do not have access to ENVI Lidar.

- Terrasolid software involves a large amount of preprocessing, and has a fairly high level of laser scanning data processing. The software allows us to perform fine tuning and to extract the largest amount of vector information, in particular roof slopes, which is very important for Smart City projects. An important advantage of this software is a flexible connection with CAD programs.

- Erdas IMAGINE is most suitable for environmental tasks, due to the possibility of working with multispectral images. The processing performance of point clouds is the lowest of the examined ones, but at the same time it allows solving spatialanalysis tasks. The main advantage of Erdas IMAGINE is its good and flexible connection with GIS.

- Autodesk InfraWorks and allow us to get very quickly the raw result, analyze the study area and create information support for a feasibility study.

Quantitative comparison of the quality of classification by the number of points in each class shows a significant variation. This is talking about the imperfection of the automatic classification and the relevance of this direction of further research.

\section{ACKNOWLEDGEMENTS}

The research is carried out with the financial support of the Ministry of Science and Higher Education of Russian Federation within the framework of the Federal Program "Research and Development in Priority Areas for the Development of the Russian Science and Technology Complex for 2014-2020". The unique identifier of the project is RFMEFI58417X0025.

\section{REFERENCES}

Angelidou, M. 2017. The role of smart city characteristics in the plans of fifteen cities. Journal of Urban Technology, 24(4), 328. doi.org/10.1080/10630732.2017.1348880

Badenko, V., Fedotov, A., Vinogradov, K. 2018a. Algorithms of laser scanner data processing for ground surface reconstruction Lecture Notes in Computer Science (including subseries Lecture Notes in Artificial Intelligence and Lecture Notes in Bioinformatics), 10961 LNCS, 397-411. doi.org/10.1007/978-3-319-95165-2_28

Badenko V., Fedotov A., Vinogradov K. 2019. Hybrid Algorithms of Laser Scanning Point Cloud for Topological 
Analysis //Advances in Intelligent Systems and Computing, 797, 223-234. doi.org/10.1007/978-981-13-1165-9_20

Badenko, V., Volgin, D., Lytkin, S. 2018b. Deformation monitoring using laser scanned point clouds and BIM. MATEC Web of Conferences, 245, 01002.

doi.org/10.1051/matecconf/201824501002

Balado, J., Díaz-Vilariño, L., Arias, P., González-Jorge, H. 2018. Automatic classification of urban ground elements from mobile laser scanning data. Automation in Construction, 86, 226-239. doi.org/10.1016/j.autcon.2017.09.004

de Carvalho, O., Guimarães, R., Montgomery, D., Gillespie, A., Trancoso Gomes, R., de Souza Martins, É., Silva, N. 2014. Karst depression detection using ASTER, ALOS/PRISM and SRTM-derived digital elevation models in the Bambuí Group, Brazil. Remote Sensing, 6(1), 330-351. doi.org/10.3390/rs6010330

Chen, L., Zhao, S., Han, W., Li, Y. 2012. Building detection in an urban area using lidar data and QuickBird imagery. International Journal of Remote Sensing, 33(16), 5135-5148. doi.org/10.1080/01431161.2012.659355

Gorte, B., Pfeifer, N., Elberink, S. O. 2005. Height texture of low vegetation in airborne laser scanner data and its potential for DTM correction. International Archives of the Photogrammetry, Remote Sensing and Spatial Information Sciences- ISPRS Archives, 36(3/W19), 150-155.

Hu, P., Yang, B., Dong, Z., Yuan, P., Huang, R., Fan, H., Sun, X. 2018. Towards Reconstructing 3D Buildings from ALS Data Based on Gestalt Laws. Remote Sensing, 10(7), 1127. doi.org/10.3390/rs10071127

Jochem, A., Höfle, B., Wichmann, V., Rutzinger, M., Zipf, A. 2012. Area-wide roof plane segmentation in airborne LiDAR point clouds. Computers, Environment and Urban Systems, 36(1), 54-64.

doi.org/10.1016/j.compenvurbsys.2011.05.001

Julin, A., Jaalama, K., Virtanen, J. P., Pouke, M., Ylipulli, J., Vaaja, M., Hyyppä, J, Hyyppä, H. 2018. Characterizing 3d city modeling projects: Towards a harmonized interoperable system. ISPRS International Journal of Geo-Information, 7(2), 55. doi.org/10.3390/ijgi7020055

Kaartinen, H., Hyyppä, J., Kukko, A., Jaakkola, A., Hyyppä, H. 2012. Benchmarking the performance of mobile laser scanning systems using a permanent test field. Sensors, 12(9), 1281412835. doi.org/10.3390/s120912814

Li, J., Yao, Y., Duan, P., Chen, Y., Li, S., Zhang, C. 2018. Studies on Three-Dimensional (3D) Modeling of UAV Oblique Imagery with the Aid of Loop-Shooting. ISPRS International Journal of Geo-Information, 7(9), 356. doi.org/10.3390/ijgi7090356

Lindenthal, S.M., Ussyshkin, V.R., Wang, J.G., Pokorny, M. 2011. Airborne LiDAR: A fully automated selfcalibration procedure. International archives of the Photogrammetry, Remote Sensing and Spatial Information Sciences - ISPRS Archives, 38(5W12), 73-78
Muecke W., Briese C., Hollaus M. 2010. Terrain echo probability assignment based on full-waveform airborne laser scanning observables. International Archives of the Photogrammetry, Remote Sensing and Spatial Information Sciences - ISPRS Archives, 38, 157-162

Nevalainen, P., Middleton, M., Sutinen, R., Heikkonen, J., Pahikkala, T. 2016. Detecting terrain stoniness from airborne laser scanning data. Remote Sensing, 8(9), 720. doi.org/10.3390/rs8090720

Penner, M., Woods, M., Pitt, D. 2015. A comparison of airborne laser scanning and image point cloud derived tree size class distribution models in boreal Ontario. Forests, 6(11), 40344054. doi.org/10.3390/f6114034

Robinson, N., Regetz, J., Guralnick, R. P. 2014. EarthEnvDEM90: A nearly-global, void-free, multi-scale smoothed, $90 \mathrm{~m}$ digital elevation model from fused ASTER and SRTM data. ISPRS Journal of Photogrammetry and Remote Sensing, 87, 57-67. doi.org/10.1016/j.isprsjprs.2013.11.002

Tomljenovic, I., Höfle, B., Tiede, D., Blaschke, T. 2015. Building extraction from airborne laser scanning data: An analysis of the state of the art. Remote Sensing, 7(4), 38263862. doi.org/10.3390/rs70403826

Tran, T., Ressl, C., Pfeifer, N. 2018. Integrated change detection and classification in urban areas based on airborne laser scanning point clouds. Sensors, 18(2), 448. doi.org/10.3390/s18020448

Wang, Y., Chen, Q., Liu, L., Li, X., Sangaiah, A., Li, K. 2018. Systematic comparison of power line classification methods from ALS and MLS point cloud data. Remote Sensing, 10(8), 1222. doi.org/10.3390/rs10081222

Xiao, W., Vallet, B., Schindler, K., Paparoditis, N. 2016. Streetside vehicle detection, classification and change detection using mobile laser scanning data. ISPRS Journal of Photogrammetry and Remote Sensing, 114, 166-178. doi.org/10.1016/j.isprsjprs.2016.02.007

Yan, W. Y., Shaker, A., El-Ashmawy, N. 2015. Urban land cover classification using airborne LiDAR data: A review. Remote Sensing of Environment, 158, 295-310. doi.org/10.1016/j.rse.2014.11.001

Yang, B., Lee, J. 2019. Improving accuracy of automated 3-D building models for smart cities. International Journal of Digital Earth, 12(2), 209-227. doi.org/10.1080/17538947.2017.1395089

Zhou, L., Vosselman, G. 2012. Mapping curbstones in airborne and mobile laser scanning data. International Journal of Applied Earth Observation and Geoinformation, 18, 293-304. doi.org/10.1016/j.jag.2012.01.024

Zubizarreta, I., Seravalli, A., Arrizabalaga, S. 2015. Smart city concept: What it is and what it should be. Journal of Urban Planning and Development, 142(1), 04015005. doi.org/10.1061/(ASCE)UP.1943-5444.0000282 